
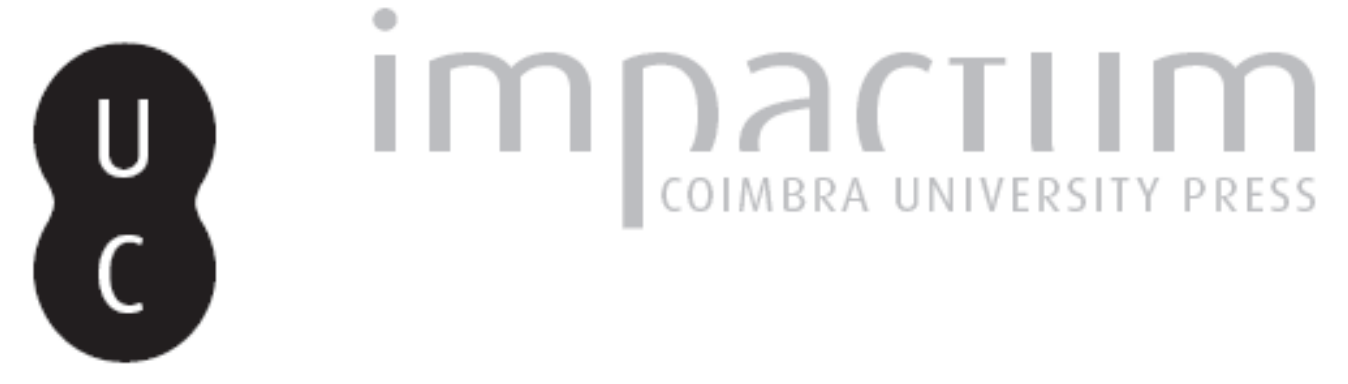

\title{
Voz do avatar, voz como avatar, avatar da voz
}

\section{Autor(es): $\quad$ Serra, Pedro}

Publicado por: Centro de Literatura Portuguesa; Imprensa da Universidade de Coimbra

URL persistente:

URI:http://hdl.handle.net/10316.2/37782

DOI:

DOI:http://dx.doi.org/10.14195/2182-8830_3-1_1

Accessed : $\quad$ 26-Apr-2023 16:12:16

A navegação consulta e descarregamento dos títulos inseridos nas Bibliotecas Digitais UC Digitalis, UC Pombalina e UC Impactum, pressupõem a aceitação plena e sem reservas dos Termos e Condições de Uso destas Bibliotecas Digitais, disponíveis em https://digitalis.uc.pt/pt-pt/termos.

Conforme exposto nos referidos Termos e Condições de Uso, o descarregamento de títulos de acesso restrito requer uma licença válida de autorização devendo o utilizador aceder ao(s) documento(s) a partir de um endereço de IP da instituição detentora da supramencionada licença.

Ao utilizador é apenas permitido o descarregamento para uso pessoal, pelo que o emprego do(s) título(s) descarregado(s) para outro fim, designadamente comercial, carece de autorização do respetivo autor ou editor da obra.

Na medida em que todas as obras da UC Digitalis se encontram protegidas pelo Código do Direito de Autor e Direitos Conexos e demais legislação aplicável, toda a cópia, parcial ou total, deste documento, nos casos em que é legalmente admitida, deverá conter ou fazer-se acompanhar por este aviso.

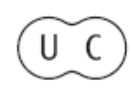




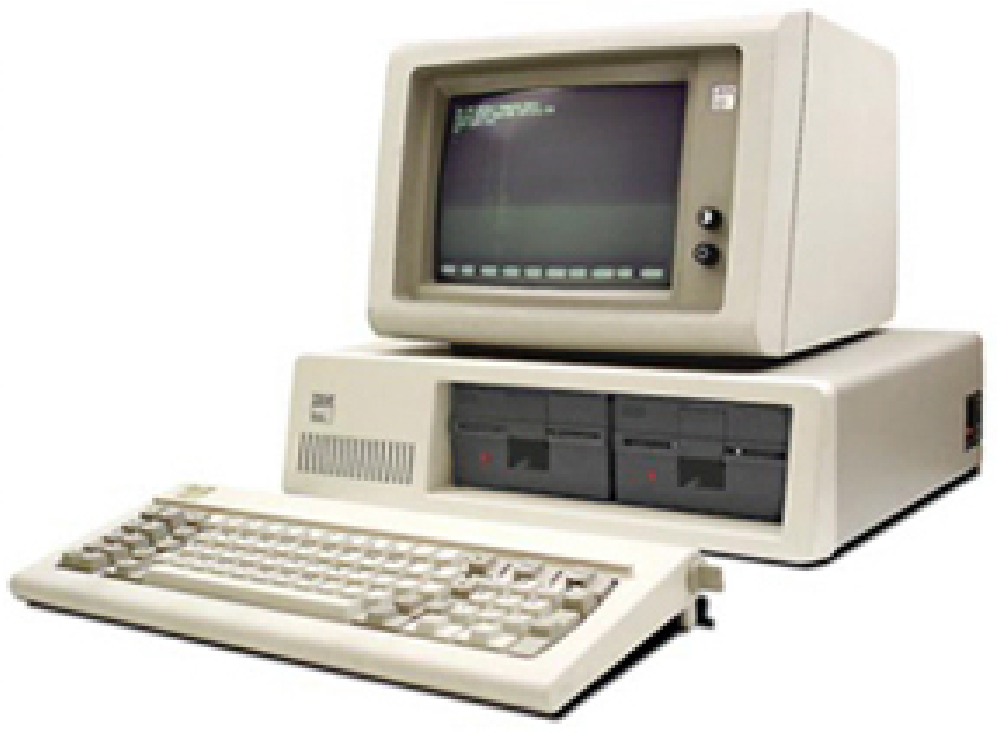

Vol. 3.1 (2015)

ISSN 2182-8830

'Artes, Média e Cultura Digital'

Paulo Silva Pereira e Pedro Serra (orgs.) 


\title{
Voz do Avatar, Voz como Avatar, Avatar da Voz PEDRO SERRA
}

\author{
Universidade de Salamanca
}

\begin{abstract}
Resumo
O meu artigo propõe um exercício de arqueofonia - ou arqueologia da voz - que incide, nesta oportunidade, sobre a possibilidade de estabelecer a complexa figura e imaginação do 'avatar' como comparandum da noção e representação do cyborg. As valências da comparação permitem pensar diferentes objectos, como sejam a 'voz do avatar', a 'vOz como avatar' e, finalmente, o arquivo das representações da voz, 'avatares da voz'. Em jeito de crítica aplicada, são sucintamente comentados o filme Her, de Spike Jonze; fragmentos do Livro do Desassossego, de Bernardo Soares/Fernando Pessoa; e, por último, a simulação digital da voz de John Donne acessível em linha, corolário do Virtual Paul's Cross Project. A Digital Re-Creation of John Donne's Gunpowder Day Sermon, sediado na North Carolina State University. Palavras-chave: arqueofonia; voz; avatar; cyborg; heterónimo como avatar.
\end{abstract}

\section{Abstract}

My article proposes an exercise of archeophony - or voice archeology - focusing, on this occasion, on the possibility of establishing the complex figure and imagining of the 'avatar' as a comparandum of the notion and representation of the 'cyborg'. The gains of this comparison allow us to debate different objects, such as 'the voice of the avatar', the 'voice as avatar' and, finally, the archive of the vocal representations, 'avatars of the voice'. Case studies under concise scrutiny include Spike Jonze's feature film Her, fragments of the Bernardo Soares/Fernando Pessoa's Book of Disquiet, lastly, the digital simulation of John Donne's voice, accessible online as a result of the Virtual Paul's Cross Project: A Digital Re-Creation of John Donne's Gunpowder Day Sermon, based at the North Carolina State University. Keywords: archeophony; voice; avatar; cyborg; heteronym as avatar.

$\mathbf{U}$ $\mathrm{m}$ dos últimos ícones mais instigantes, e decerto ainda hoje valioso, da recente analítica cultural é aquele que veio a ter uma caução teórica num famoso pronunciamento de Donna Haraway, publicado em meados da década de oitenta do século XX (cf. Haraway, 1985), amplamente difundido e glosado nas décadas seguintes. Refiro-me, claro está, à figura do cyborg, o híbrido humano/máquina que, por esses idos ainda de euforia académica pela teoria, atravessou o imaginário social e das práticas discursivas, habitando tanto a imaginação e o pensamento em sede universitária como assolando o pensamento e a imaginação da chamada contracultura, muito especificamente da ficção, primeiro romanesca e depois cinematográfica, cyberpunk. Daí a condição icónica do cyborg, precisamente, uma icono- 
logia e iconografia que chega aos nossos dias, e mesmo aos tempos mais próximos da teoria. Num recente e belíssimo livro intitulado La melancolia del ciborg, Fernando Broncano, professor de filosofia da ciência da Universidade Carlos III de Madrid, modelizou uma nova versão do ícone a que Donna Haraway, no seu conhecido Manifesto for Cyborgs, concedeu um primeiro impulso conceptual e imagético. A 'melancolia' a que se refere Broncano, sintoma peculiarmente moderno como argumenta, é aquela que define o 'humano' consciente de ser produzido, latamente, pela tecnologia. Isto é, trata-se de uma nostalgia infinita, impiedosa, por um objecto que não pode não ser indexado ao sublime: uma natureza perdida.

Os humanos não estão inacabados, as suas técnicas, as suas próteses, os contextos de artefactos em que os seus antepassados hominídeos constituíram-nos como espécie: não necessitam da técnica para se completar, são um produto da técnica. São, foram, seremos o que chamarei seres cyborg, seres feitos de materiais orgânicos e produtos técnicos, como o barro, a escrita e o fogo. (Broncano 2009: 19-20) ${ }^{1}$

O que move, então, cabe perguntarmo-nos, aquela 'melancolia do cyborg', aquela nostalgia de uma natureza que nunca foi? É aqui que a modelização do ícone levada a cabo por Fernando Broncano revela o seu poder de leitura e interpretação: a 'melancolia' é o resultado de um atrito, de uma fricção: o contínuo protésico de que emana o humano é incorporado por uma dialética entre choque e habituação, estranhamento e familiaridade.

Seja como for, a iconologia e iconografia do cyborg, do meu ponto de vista, acaba por ser determinada por um modelo instrumental da técnica e da tecnologia, legado moderno que tem mobilizado tanto a utopia como a distopia, tanto as recidivas humanistas como as anti-humanistas. Pensar e imaginar o cyborg - o que, no fundo, e em rigor, supõe o pensamento e a imaginação como cyborg -, é determinado por um quadro especulativo em que a hipóstase de binómios, de que somos legatários, como humano/máquina ou natural/artificial, não subsume a possibilidade da sua implosão. Efectivamente, tanto a tradição humanista oitocentista, que vê na tecnologia uma ampliação das capacidades físicas ou intelectuais do ser humano, como um certo pós-humanismo da segunda metade do século XX, instrumentalizam o que latamente podemos chamar 'tecnologia'. Esse pós-humanismo, ou mesmo anti-humanismo, pôde ter, por exemplo, na seguinte imagem J. G. Ballard uma poderosa figuração. Afirma a voz em off do próprio Ballard em Crash!, pequeno filme produzido pela BBC e dirigido por Harley Cokliss em 1971 a partir de fragmentos da Atrocity Exbibition, título do romance homónimo de Ballard que só viria a ser publicado em 1973: "the future is something with a

${ }^{1}$ Salvo indicação contrária, as traduções para a língua portuguesa dos textos citados são da minha responsabilidade. 
fin on it". ${ }^{2}$ Magistral síntese do fascínio e temor - modos maiores da ficção científica e da ficção cyberpunk - que move a tecnologia avançada, estranhando e entranhando-se no mundo da vida.

O cyborg, quero crer, é ainda esse ponderoso e poderoso Outro, seja como ameaça de despossessão do que seria próprio ao ser humano - sobretudo, ao corpo humano deposto da sua sacralidade -, seja como catalisador dessa propriedade humana como projecção. Também isto assenta o excelente livro La melancolía del ciborg. De forma lapidar, Fernando Broncano afirma que, em última instância, isto é, nesse lugar último a que conduz a infinita 'melancolia do cyborg', "Os cyborgs já não são humanos" (25). A 'melancolia', enfim, perfaz o seu trabalho negativo: o que define o humano é também o que o indefine. Instala-se, assim, uma aporética: cyborg é tanto o nome como o inominável. Por outras palavras, o cyborg figura latamente valências e limites da problemática moderna da representação. Ora bem, a tecnologia como instrumento - e é ela que está em causa, no fundo, no quadro especulativo exemplar brevemente exposto -, como sabemos e, sobretudo, somos especialmente conscientes do facto com a superveniência do chamado digital turn, não é o único paradigma intelectual para pensar as tensões no âmago tanto da autoreflexão como da agência humanas.

$\mathrm{Na}$ verdade, é possível extrair consequências teóricas e práticas de um outro paradigma, um paradigma que não requer sequer a relação e intensão que se foi estabelecendo entre a mediologia analógica e os meios digitais. A instrumentalização da tecnologia, consabida herança oitocentista, como já sublinhei, responde por um modelo de agência e auto-reflexão que tem no 'homo faber' a sua latência figural. Pois bem, como propôs Vilém Flüsser de forma especialmente feliz, muito condensada e certamente com ponderosas consequências para o pensamento da complexa e ampla matéria em pauta matéria que tão-somente poderei sumariar, neste texto, nalguns dos seus aspectos essenciais -, aquilo a que chama aparelhos podem ser brinquedos. Flüsser, num importante livro intitulado em língua portuguesa Filosofia da Caixa Preta, e, em língua inglesa, Towards a Philosophy of Photography, incidindo sobre as "imagens técnicas" - isto é, sobre as imagens que são produzidas por máquinas no sentido que a revolução industrial imprime ao termo; por exemplo, as máquinas fotográficas -, no modo quase aforístico que é o seu, formulou:

Uma câmara não é um instrumento mas sim um brinquedo, e um fotógrafo não é um trabalhador, mas sim um jogador. Não tanto um Homo Faber, mas antes um Homo Ludens. E o fotógrafo não brinca com o seu brinquedo, mas contra ele. Penetra no aparelho com o intuito de descobrir-lhe os truques (27).

2 Filme disponível online em https://www.youtube.com/watch?v=5cqn6zA1sMg. A frase de Ballard encontra-se no minuto 03:15s a 03:17s. 
Eis, então, o cerne de um outro paradigma que permite pensar aquilo a que chamamos tecnologia: entendê-la, a partir da revolução industrial enfim, naquele cronótopo de uma 'Modernidade' pós-ilustrada -, não na sua dimensão instrumental que a própria industrialização produz, mas naquilo que já nesse contexto aponta para a sociedade pós-industrial (cf. ibidem: 26): a tecnologia como brinquedo, e, consequentemente, o correlato de uma agência humana que tem a sua figuração mais ajustada no bomo ludens, síntese formal de diferentes epifenómenos de auto-representação humana.

A importância da câmara fotográfica como brinquedo, o seu uso como jogo e o seu usuário como jogador tem, para Vilém Flüsser, um interesse que a excede como aparelho diferenciado, constituindo, na verdade, um novo paradeigma da tecnologia, abrangendo desde dispositivos macrodimensionados como pode ser um Estado, ou de escala microscópica como um chip electrónico. Não me vou deter aqui, de momento, mas gostaria, contudo, de sublinhar ainda uma tipologia conformada pelo filósofo checo - durante muitos anos radicado no Brasil, concretamente em São Paulo - que, como argumentarei, tem valências heurísticas para o tema proposto, "Voz do avatar, voz como avatar, avatar da voz". Pois bem, distingue Flüsser três figuras na relação com os aparelhos. Assim: "Ao contrário dos artesãos, rodeados pelas suas ferramentas, e dos operários fabris posicionados diante das máquinas, os fotógrafos estão dentro dos aparelhos e atados a eles" (27). Estar dentro e atado a um aparelho, distinguindo-se do pré-industrial artesão e do operário industrial, significa que o fotógrafo é o que chama um 'funcionário'. Cito uma última vez palavras do autor de Filosofia da Caixa Preta: "Esta é uma nova função na qual os seres humanos não são nem a constante nem a variável, mas sim uma função na qual seres humanos e aparelhos se fundem numa unidade" (27). Ser artesão significava ser, o humano, a constante de uma variável que era a ferramenta; no operário, por seu turno, o humano devém a variável de que a máquina é a constante; o funcionário, enfim, supõe a implosão desses termos contrários de variabilidade e constância.

A ser correcta a minha leitura, e espero aduzir argumentos convincentes, talvez possamos comutar a iconologia e iconografia do cyborg por um outro ícone a que a 'guinada digital' veio conceder, nas últimas décadas, uma nova expressão. Refiro-me ao avatar que, como o cyborg, teve uma nova vida no subgénero da ficção-científica conhecido como gyberpunk, caldo de cultura de onde emanaram muitas formas e figurações que habitam a imaginação dos videojogos, do cinematógrafo, do cinema digital, enfim, das interfaces e do software que determinam o 'mundo da vida' desde há várias décadas. Para esclarecer o meu argumento, impõem-se algumas considerações e ressalvas prévias, necessariamente breves. Em primeiro lugar, a proposta de comutar a figura do cyborg pela figura do avatar não significa subtrair valor heurístico à primeira. $\mathrm{Na}$ verdade, cyborgs e avatares implicam-se mutuamente. Contudo, a dominante protética do cyborg, a dimensão analógica que carreia, distingue-se 
do avatar ao se dimensionar, este, como simulação. No avatar importa a manifestação simulada de uma experiência da percepção e da consciência.

Por outro lado, sublinho ainda que por avatar não devemos entender, apenas, a iconografia que os meios digitais vieram a conformar, uma conformação, aliás, francamente multímoda e multiforme. Derrick de Kerckhove, discípulo de Marshall MacLuhan, num recente ensaio intitulado "Avatar = Pinocchio 2.0 or "The end of the Society of the Spectacle" proporcionou, do meu ponto de vista, uma descrição não totalmente satisfatória do termo no contexto da tecnologia digital, mas que ainda assim é elucidativa:

o avatar é uma projecção de mim mesmo assistida por computador num ambiente externo, razão pela qual se trata de uma projecção objectiva. $\mathrm{O}$ usuário pode escolher entre olhar o mundo virtual a partir do seu próprio ponto de vista ou então ver-se a si mesmo como um conteúdo, como parte da cena. O avatar digital está fora do nosso corpo, sobre um écran. Converte-se em parte de um imaginário objectivo e compartilhado (10).

Reconheço aqui o eco, quero crer, da consabida definição, levada a cabo por William Gibson, do ciberespaço como "alucinação consensual”; a descrição de Kerkhove é valiosa mas não totalmente cabal porque não incide sobre a noção de que o avatar é figura de um tipo de experiência perceptiva e da consciência que tem um amplo arquivo na "liminariedade" ou metaxis" que supõe a transgressão simulada das determinações do 'mundo da vida', magistralmente sintetizadas por Hans Ulrich Gumbrecht: a. ocupação de dois espaços em simultâneo; b. integração na mente de um outro; c. desincorporação e reincorporação na sensorialidade de um outro; d. produção de experiências directas anteriores ao nascimento (cf. Gumbrecht, 1992: 50). ${ }^{4}$ Assim,

\footnotetext{
3 Augusto Boal, que recupera a noção de Platão e Voegelin, descreve assim a metaxis: "[O] estado de pertença completa e simultânea a dois mundos diferentes e autónomos: a imagem da realidade e a realidade da imagem. O participante partilha e pertence a estes dois mundos autónomos; a realidade deles e a imagem da sua realidade, que ela própria produziu" (43; eu traduzo).

${ }^{4}$ Tenha-se presente a seguinte síntese: "Mencionámos a premissa sócio-antropológica segunda a qual as estruturas do mundo da vida compensam a ausência de instintos humana. As estruturas do mundo da vida efectuam esta função estabelecendo limites para cada mundo quotidiano - por outras palavras, excluindo certos conteúdos da consciência de todos os mundos quotidianos. Por exemplo, não é possível estar em vários lugares ao mesmo tempo; não é possível experimentar directamente o que aconteceu antes de nascermos; não é possível conhecer categoricamente o que se está a passar na mente de outras pessoas; não é possível sair no nosso próprio corpo. Significativamente, apenas Deus 'é' omnipresente, 'não tem' princípio ou fim, 'é' omnisciente e 'é' puro espírito. Decerto, esta predicação divina apenas mostra que os conteúdos da consciência, que as estruturas do mundo da vida excluem de mundos quotidianos concretos como objectos da experiência humana (tanto como Erleben como Erfabrung), podem ser simulados pela linguagem" (Gumbrecht, 1992: 50; eu traduzo). A linguagem, nesta descrição, detém uma potencialidade: a da simulação.
} 
das estátuas articuladas dos templos egípcios, aos cristos articulados do barroco espanhol e aos autómatos; das máscaras das culturas indígenas, às máscaras do teatro ou às marionetas ventríloquas, temos uma amostra de diferentes objectos e formas que integram o arquivo da experiência liminóide ${ }^{5}$ a que pertencem também os avatares $3 \mathrm{D}$ dos chamados mundos virtuais como Second Life.

Entretanto, uma terceira ressalva diz respeito a algo como as figurações do avatar, entendida a palavra nos termos que acabo de descrever em jeito necessariamente sumário. $\mathrm{O}$ híbrido biotecnológico figurado pelo cyborg, negativo pela sua condição mortal, proporcionou uma reflexão sobre a égide da 'crise da representação'. Algo que provém da matriz teórica, se recordarmos a consabida proclamação utópica pós-genérica, em meados dos anos oitenta, de Donna Haraway: "I would rather be a cyborg than a goddess" (108). Ora, reside aqui, neste sentido, a valência do avatar, que permite pensar, ao invés, a questão da presença. $\mathrm{Na}$ minha descrição, precisamente, o avatar é uma figura maior da simulação da presença. O grau de imiscuição de bios e technos na figuração avatárica, assim, supõe aquela implosão do valor heurístico e epistemológico do binómio constante/variável na relação do humano e da máquina de que fala Vilém Flüsser.

Sublinho, enfim, uma quarta e última ressalva. A entrada que vou fazer no avatar como figura da simulação da presença determinada pelas condições de possibilidade materiais e tecnológicas do artesão pré-moderno, do operário moderno e do funcionário que lhe sobrevém, incidirá num subtipo de figuração que é a da voz avatarizada. A iconologia e a iconografia desta voz avatarizada - a voz do avatar, a voz como avatar, o avatar da voz -, do meu ponto de vista, demanda um dispositivo multidisciplinar e multimedial de leitura que tem, em última instância, o objectivo de conformar um modelo interpretativo da 'não naturalidade' da voz humana - a voz é o mais inumano desse constructo vário, variamente modelizado, que é 'humano' -, voz humana que foi sendo, na verdade, um dos mais estáveis objectos naturalizados, por exemplo, disso a que chamamos literatura, cruzando as tecnologias analógicas e digitais que são a sua condição de possibilidade. Se, como propõe Hans Ulrich Gumbrecht, é possível 'contar como história' a aparente continuidade de um conjunto de manifestações discursivas "que não parec[em] ser nem impulsionad[as] por um princípio básico específico, nem estar subordinad[as] a um determinado objectivo" (Gumbrecht, 1998: 301) - a literatura como média, a literatura como meio comunicativo -, creio ser plausível conceber diferentes etapas da 'voz' tanto na literatura como noutras formas simbólicas e respecti-

\footnotetext{
5 "Liminar" traduz, aqui, o termo "liminal" cunhado por Victor Turner com o seguinte sentido: "[o termo] descreve o limite entre o espaço da experiência normal e o espaço em que acontecem os rituais; isto pode também ser aplicado a qualquer espaço formal estruturado com um sistema semiótico incrementado, como teatros ou jogos, mas como estes espaços são normalmente menos estruturados e formalizados, Victor Turner chama-lhes liminóides" (Kuksa e Childs, 2014: 166).
} 
vos suportes materiais. Desde logo porque a 'voz como avatar' é um objecto em que conflagram e se equacionam os dois eixos que determinam o meio da literatura ou a literatura como meio: a 'presença à distância', por um lado, e as 'relações de asseveração' que lhe estão vinculadas, das quais a 'proximidade psico-intelectual' autor/leitor' é um dos travejamentos da literatura como média cujo advento se associa à invenção da máquina tipográfica, remediado, entretanto, por outros meios analógicos - como a gramofonia -, ou pelo meio de meios que é o digital.

Efectivamente, tanto uma página impressa como o próprio livro fasciculado - superfícies da escrita que virtualiza verba e vox -, suportes da literatura, são modelos de caixas de ressonância da simulação da voz, da presença da vOZ como simulacro. Considero ser produtivo tentar extrair consequências dessa voz como presença ou, enfim, como avatar: a voz avatarizada entendo-a, neste sentido, como objecto virtual - nem concreto, nem abstracto - que se move numa superfície plana, por exemplo, numa página impressa, num registo fonográfico ou num écran, entendendo-o quer como suporte analógico, quer digital.

Aponto, neste sentido, e em jeito de crítica prática de um quadro especulativo a que me venho referindo como 'arqueofonia' (cf. Serra, 2010, 2012 e 2014), ${ }^{6}$ três exempla, uma drástica redução fenomenológica que, contudo, espero possa contribuir para concretizar o que o meu título promete. Desde logo, seria cair no óbvio alegar a necessidade e valor deste tipo de reducionismo para enfrentar os desafios colocados, hoje, aos estudos humanísticos. Os exemplos que conjuro, neste sentido, são amostras suficientes, do meu ponto de vista, para ilustrar as possibilidades heurísticas das três figuras propostas por Vilém Flüsser, e que recordo: o artesão, o operário e o funcionário, amplexo de figuras que permite matizar o marco especulativo da relação homem/máquina. Farei cronologia inversa, alinhando três objectos que nos proporcionam uma amostragem da voz. como avatar: o filme Her, estreado já no século XXI, do cineasta norte-americano Spike Jonze; o chamado Livro do

${ }^{6} \mathrm{Na}$ origem destas publicações encontram-se as seguintes conferências: "Física virtude das palavras. Notas sobre a poesia e a poética de Francisco Manuel de Melo", apresentada ao congresso internacional D. Francisco Manuel de Melo e o Barroco Peninsular, Universidade de Coimbra, Coimbra, 23-25.11.2008; "Lira antártica. Arqueologias da voz em D. Francisco Manuel de Melo e António Franco Alexandre”, apresentada ao $5^{\circ}$ Colóquio do PPRLB. O Atlântico como Ponte: a Europa e o Espaço Lusófono II, Real Gabinete Português de Leitura, Rio de Janeiro, 14.09.2010; “Arqueofonias. Língua do império e arqueologias da voz na poesia pós-25 de Abril: o caso de António Franco Alexandre", apresentada ao congresso From the Republic to April 25, 1974: The Empire as Mirage, Ohio State University, Columbus, 04.11.2010; “As vozes saem do ar, e não de gargantas. Metaforologias do som e da voz humana no Livro do Desassossego", apresentada ao congresso Livro do Desasocego: Perspectivas, Universidade de Lisboa, 6-7.12.2012; "Arqueofonia ou arqueologia da voz: noções, meios, casos", conferência de inauguração das actividades como Professor Visitante CAPES/PVE, a convite de Marcos Siscar, apresentada no Instituto de Estudos da Linguagem (IEL), Unicamp, Campinas (São Paulo), 12.03.2013. 
Desassossego de Bernardo Soares/Fernando Pessoa, fantasma que assombra a possibilidade de uma modernidade declinada em língua portuguesa; e, por último, para o século XVII, o sermão que John Donne profere a 5 de Novembro de 1622 no adro da Catedral de São Paulo, em Londres, por ocasião do chamado Gunpowder Day. Este caso, que ilustra a 'voz como avatar' na mais espinhosa pré-modernidade, requer que faça referência ao jesuíta alemão Athanasius Kircher, autor de Phonurgia Nova, importante tratado de acústica publicado em 1650.

Ora, poderíamos começar por assentar que, dum ponto de vista cinematográfico, a impressionante personagem de Samantha do filme de Spike Jonze é predicada pelos atributos da 'voz acusmática' écranizada que genialmente teorizou Michel Chion: "Ao estar no écran sem estar nele, ao vagar pela superfície do écran sem adentrar-se nele, o acusmaser é o factor de desequilíbrio, de tensão" (36). Samantha é um "acusmaser", sim, mas é também a imaginação de um sistema operativo - em rigor, um brinquedo - sentiente e consciente. O que me parece fascinante na personagem a que empresta voz a actriz Scarlett Johansson é que nos conforma a voz como avatar de um sistema operativo capacitado de auto-reflexividade intelectual e sensível. Diferentes leituras do filme têm insistido, talvez com demasiada celeridade, na 'ausência' de corpo como atributo da personagem Samantha. Não é assim, do meu ponto de vista: o corpo de Samantha é a sua voz sintetizada, suporte de um objecto ontológico cuja existência - isto é, cuja simulação de presença depende da intersubjectividade sensorial e intelectual do protagonista, Theodor Twombly. A avatarização é multímoda e multiforme, pois tanto Samantha é avatar de Theodor, como Theodor é avatar de Samantha, ou pode mesmo admitir surrogate bodies. A voz digital é o corpo de Samantha; no fundo, é uma voz inumana, mas em rigor no sentido de que também o é a própria voz humana: só existe na separação do corpo - torna-se corpo para além do corpo -, vOz avatar determinada por tecnologias que a estruturam e repetem, sendo paradoxal suporte da ficção que é a de uma consciência íntima capaz de acção subjectiva e de relação intersubjectiva. Her, enfim, trata-se de filme de ficção científica em que a tecnologia absolutiza, dissolvida sem atrito, o 'mundo da vida' - não ficando claro se se trata de uma utopia ou de uma distopia - e em que teremos exemplificado o funcionalismo do bomo ludens a que se refere Vilém Flüsser.

Vejamos, agora, um segundo exemplo. Para tanto, parto da premissa de que no silêncio da página impressa que a Modernidade agoniza, a 'imagem acústica' - podemos, por exemplo, pensar na modulação saussuriana desta noção - supõe algo como a alucinação da voz de um texto sobrevivendo à sua inscrição (cf. Derrida, 1996: 62). Ora, considero que também aqui o avatar da voz, figura de uma presença espectralizada - isto é, simulada -, tem a sua valência. Noutro lugar, aproximo-me com mais pormenor desta questão no que se refere ao Livro do Desassossego (cf. Serra, 2015), mas permito-me sumariar, agora, o argumento, postulando que a tropologia vocal que encon- 
tramos na obra de Bernardo Soares/Fernando Pessoa conjura materialidades e valores simbólicos que podem ser justapostos à voz como avatar. Num recorte tempestivo, lembro dois fragmentos da obra que, pelo viés da figura da voz como avatar, podem estabelecer, como marco especulativo para uma ponderação da questão mediológica da obra pessoana, a figura do operário tal como a descreve Flüsser. Lemos a páginas tantas no Livro do Desassossego:

Dispenso e detesto vehículos, dispenso e detesto os productos da sciencia - telephones, telegraphos - que tornam a vida fácil, ou os subprodutos da fantasia - gramophonographos, receptores hertzianos - que, aos a quem divertem, a tornam divertida (365).

Por outro lado, num fragmento datado de 3 de Dezembro de 1931 - na etapa tardia de redacção do Livro, por conseguinte -, lemos, neste sentido:

Tenho ganas de gritar dentro da cabeça. Quero parar, esmagar, partir esse impossível registo gramophonico que soa dentro de mim em casa alheia, torturador intangivel. Quero mandar parar a alma, para que ella, como vehiculo que me ocupassem, siga para deante e me deixe (348).

Estes trechos podem ser o ponto de partida para pensarmos os heterónimos pessoanos como avatares, mais precisamente como vozes avatarizadas. ${ }^{7}$ No fundo, o objecto figurado neste segundo fragmento - aquele 'veículo anímico que segue adiante e o deixa' -, um objecto que adquire exterioridade e autonomia, descreve uma voz como avatar, cujas materialidades, no caso de Bernardo Soares/Fernando Pessoa, demandam a remediação e intermediação entre tipografia e gramofonia. Enfim, estes loci recortados do 'anarquivo' de fragmentos chamado Livro do Desassossego, mostram-nos um Bernardo Soares/Fernando Pessoa para quem os aparelhos não são ainda um brinquedo - um Pessoa funcionário -, mas que ainda dramatiza de modo paroxístico daquela relação em que homem e aparato se justapõem, um Pessoa operário para o qual o aparato é a constante e o homem a variável.

Concluo, enfim, conjurando um exemplo seiscentista, concretamente o caso do sermão de John Donne proferido no adro da Saint Paul's Cathedral em 1622. Enceto a breve reflexão, arguindo que a possibilidade de estudar um objecto de natureza teológico-política como é a voz no bic et nunc da sua

${ }^{7}$ Luís Filipe B. Teixeira, com enfoque teórico diferente daquele que aqui implico, é o responsável pela aproximação do que chama "personagem virtual" ou "figuradispositivo" ao fenómeno heteronímico (cf. Teixeira, 1999). Deleuze e José Gil são referentes da teoria convocada para substanciar a comparação: "A heteronímia é, assim, uma máquina de produzir multiplicidades e virtualidades, de 'sentir tudo de todas as maneiras', numa operação de 'cissiparidade em abismo' (José Gil) que se repete a cada instante, de tal modo que ninguém é o mesmo a cada momento" (17). 
'actualização' - e é isto também que se configura no avatar da voz como presença da simulação -, reside no facto, já anteriormente assentado, de a vOz ser inextricavelmente determinada por dispositivos que a repetem, máquinas em que a voz tem de ser incorporada para acontecer. Refiro-me, por exemplo, a aparelhos que asseguram a possibilidade de audição da voz, ou seja, dispositivos que produzem a sua repetibilidade. Ora, é o caso da chamada statua citophonica, inventada por Athanasius Kircher na sua Phonurgia Nova, de 1673, um tratado que, como ostenta o título, constitui um "novo método de produção de som", obra em cuja segunda parte - "Phonosophia anacamptica" - o jesuíta, autor da bem mais conhecida Musurgia Universalis, investiga a propagação do som em espaços fechados que funcionam como aparelhos de ressonância. Um aparelho gémeo dos espaços fechados como meio de que depende o som - é o 'meio' que possibilita o som, na medida em que o som é "resultado de uma força que causa que um objecto vibre" (Aukstakalnis et alii, 1992: 103) - destacaria, justamente, a statua citophonica ou 'estátua falante', amplamente descrita no capítulo XI do primeiro livro de Kircher.

A statua citophonica devolve-nos o próprio 'corpo humano' concebido como caixa ressonante, como aparelho de repetição sónica onde o som propalado supõe uma realização exteriorizada mas também uma concretização interna. Concepção e imaginação com corolários ponderosos. Recorto, muito brevemente, um exemplo coevo. Num estudo soberbo, Margarida Vieira Mendes, ao desenvolver o flectere como dimensão essencial da oratória parenética do Padre António Vieira em detrimento do docere, afirma:

Encontramos lugares semelhantes nos sermões do jesuíta Francisco de Mendonça, em que o Padre António Vieira foi colher muito do seu métier oratório: o Baptista 'não era mimoso nem delicioso' (1632); 'As palavras do pregador são como aguilhões de touro, são uns pregos de palmo, que atravessam o coração [...] não sabem lisongear, sabem cortar, sabem magoar, sabem curar'; 'estes que pregam com lisonjas, e não com verdades; com palavrinhas, e não com bombadas, não são pregadores' - são 'efeminados' como mulheres (1649)" (Mendes, 1989: 169).

Ora, não seria plausível re-descrever, por exemplo, a tópica clássica dos "aguilhões de touro", fórmula da dimensão enérgica da vozactualizada, como modelização do flectere, na sua relação com a fenomenologia aristotélica do sónico - o som como resultado do movimento e choque de corpos? Ou, por outras palavras, entender a voz como corpo, emanação extática em que o que o corpo sai de si: voz como avatar, em suma.

Seja como for, a breve menção vale para reter da statua citophonica princípios como o da amplificação acústica que nos devolve, mais além da parafernália fantástica - uma espécie de paroxismo do artesão rodeado de ferramentas a que se refere, como vimos, Vilém Flüsser -, a noção de uma sonoplastia vocal como 'presença à distância' produzida por aparelhos. Assim, e como 
propõem Tronchin et alii, a statua citophonica funciona - i.e., prefigura - como um 'microfone':

O mecanismo acústico que fazia a estátua falar é, substancialmente, um microfone, que Kircher projectou como um enorme tubo espiralado com a superfície interna perfeitamente preparada para percutir as ondas (4187-4188).

Se a 'teoria' de Kircher é devedora da noção do sónico aristotélica - o som como resultado do movimento e choque de corpos -, a sua fenomenologia do som prenuncia já um outro modelo de sonoridade determinado pela teoria das ondas oscilatórias. Ora, a presença simulada da voz que o aparelho de Kircher modeliza remete-nos para as tecnologias da voz humana do tempo do sermão de John Donne, materialidades da comunicação de que é possível fazer a remediação digital. Concretamente, o Virtual Paul's Cross Project instalado no 'Teaching and Visualization Lab' da James B. Hunt Library da Universidade do Estado da Carolina do Norte, ${ }^{8}$ permite-nos, enfim, ouvir o avatar da voz de John Donne. Permite, enfim, produzir um modelo digital, uma simulação, da voz: ou melhor, permite a remediação digital da voz avatarizada de John Donne.

Um objecto, entre outros possíveis, que proponho como exemplum de uma das principais dimensões do problema da presença - enfim, a necessariamente tele-presença da voz avatarizada. Em última instância, Her, o Livro do Desassossego - ou a heteronímia, vocalidade avatarizada - e o modelo digital do sermão do Gunpowder Day proferido por John Donne no dia 5 de Novembro de 1622, são amostras do amplo arquivo da teoria e imaginação vocais. Finalmente, para retomar o primeiro andamento do meu artigo, concluo provisoriamente reiterando a hipótese de que o avatar, figura da tecnologia como brinquedo, figura do novo funcionalismo do bomo ludens, como formula Flüsser, detona o valor heurístico e epistemológico daquele atrito que encontrámos no modelo especulativo do cyborg e da sua comoção melancólica.

\section{Referências}

AUKSTAKALNIS, Steve, David Blatner e Stephen F. Roth (1992). Silicon Mirage. The Art and Science of Virtual Reality. Berkeley: Peachpit Press.

BALLARD, J. G. (2001). Crash. New York: Picador [1 $1^{\mathrm{a}}$ ed.: 1973].

BOAL, Augusto (1995). The Rainbow of Desire. The Boal Method of Theater and Therapy. Trad. Adrian Jackson. Londres/Nova Iorque: Routledge. BRONCANO, Fernando (2009). La melancolía del ciborg, Barcelona: Herder. CHION, Michel (2004). La voz en el cine. Madrid: Cátedra.

${ }^{8}$ Cf. Virtual Paul's Cross Project. A Digital Re-Creation of John Donne's Gunpowder Day Sermon. http://vpcp.chass.ncsu.edu/. 
COKLISS, Harley (1971). Crash!, com J. G. Ballard e Gabrielle Drake, Londres: BBC. 00:17m.

DERRIDA, Jacques (1996). Archive Fever. A Freudian Impression. Trad. Eric Prenowitz, Chicago: University of Chicago Press.

FLÜSSER, Vilém (2007). Towards a Philosophy of Photography. Londres: Reaktion Books [1 $1^{a}$ ed.: European Photography Edition, 1983].

GUMBRECHT, Hans Ulrich (1992). "The Role of Narration in Narrative Genres." Making Sense in Life and in Literature. Trad. Glen Burns. Minneapolis: University of Minnesota Press. 41-53.

(1998). "A mídia literatura.” Modernização dos Sentidos. Tr. Lawrence Flores Pereira. São Paulo: Editora 34. 297-319.

HARAWAY, Donna (1985). "Manifesto for cyborgs: Science, technology, and socialist feminism in the 1980s." Socialist Review 80: 65-108.

KERCKHOVE, Derrick de (2010). "Avatar = Pinocho 2.0 o 'El fin de la sociedad del espectáculo.” Digithum 12, Maio: 8-14.

KUKSA, Iryna e Mark Childs (2014). Making Sense of Space. The Design and Experience of Virtual Spaces as a Tool for Communication. Oxford: Chandos Publishing.

MENDES, Margarida Vieira (1989). A Oratória Barroca de Vieira. Lisboa: Caminho.

PESSOA, Fernando (2010). Livro do Desasocego. Ed. Jerónimo Pizarro, vol. XII, tomo I, Edição Crítica de Fernando Pessoa, Lisboa: Imprensa Nacional Casa da Moeda.

SERRA, Pedro (2012). “Arqueofonia e língua do império e na poesia pós-25 de Abril.” Relâmpago. Revista de Poesia 29-30, Fundação Luís Miguel Nava: 81-109.

(2014). "As vozes saem do ar e não de gargantas. Arqueofonias do Livro do Desassossego e da Copilaçam de Gil Vicente." Central de Poesia. O Livro do Desassossego. Eds Patrícia Soares Martins, Golgona Anghel e Fernando Guerreiro. Lisboa: LemmonSpring and Esfera do Caos Eds. 63-76.

(2015). "Avatares e heterónimos." Revista de Estudios Portugueses y Brasileños 15. Salamanca: Luso-Española de Ediciones [no prelo].

TEIXEIRA, Luís Filipe B. (1999). "Virtualidade e heteronímia. As aventuras pessoanas de Alice.” Revista Lusófona de Humanidades e Tecnologias 2, Os Universos da Comunicação. Lisboa: Universidade Lusófona: 14-18.

TRONCHIN, Lamberto, Ilaria Durvilli e Valerio Tarabusi (2008). "The Marvellous Sound World in the Phonurgia Nova of Athanasius Kircher." Proceedings of Acoustics '08 Paris. AA.VV. Paris: SFA. 4183-4188.

(C) 2015 Pedro Serra.

Licensed under the Creative Commons Attribution-Noncommercial-

No Derivative Works 4.0 International (CC BY-NC-ND 4.0). 